\section{SUGGESTIONS TO OBSERVERS OF THE SOLAR ECLIPSE OF DECEMBER NEXT}

$A N$ analysis of the observations made at the recent eclipse seems to show that it would be desirable that three or four observers should be stationed some to miles to the north or south of the limits of totality to watch for-

r. Shadow bands passing along the ground, and to note carefully the direction of their motion and their velocity. If possible this should be done upon any three planes at right angles to one another, say the ground, an east and west wall, and a north and south wall.

2. Direction and velo:ity of the wind, and also the direction and velocity of the drift of the clouds. This should be done by observers associated with those employed on $(\mathbf{I})$.

3. Kays or trushes of light from the thin cusps of the sun, and whether they alter their position and intensity.

4. Spurious red prominences from the thin crescent, noting carefully their position and size.

The following instruments might be used with advantage for polariscopic observations:-

I. A polarimeter, consisting of a Savart's polariscope mounted behind four plates of crown g'ass movable on an axis, perpendicular to the plane of polarisation, which is furnished with a graduated circle and pointer, to register the position in which the depolarisation of the plates neutralises the polarisation of the object. This should be used with a telescope having a diaphragm in the common focus restricting the diameter of the field to about $10^{\prime}$. The attention of the observer should be confined to the centre of the field (when the bands are made to disappear by rotating the plates).

2. A plate of right and left-hancled quartz attached in front of a positive eye-piece, so as to lie in the common focus of the telescope and eye-piece, with an analysing Nicol placed between the lenses of the eye-piece, which should have a field about $x^{\circ}$ in diameter.

The bi-quartz should be fixed so that the line of junction marks the plane of polarisation, giving the two halves purple alike.

The following polariscopic observations are suggested:

1. To determine the plane and measure the amount of atmospheric polarisation at at least three points, about $8^{\circ}$ or $10^{\circ}$ away from the sun's place. The points to be chosen round the sun, say N., N.E., and E., considering the sun as a map. (It would be well if three observers could be appointed each to take one fixed spot for atmospheric polarisation and to note the changes which take place during totality-both in the plane of atmospheric polarisation and in its intensity.)

2. The intensity of polarisation should be carefully measured with the polarimeter at different points of the corona, the observer taking care to notice when the Savart's bands disappear in the centre of his field as before stated.

3. The dark moon and corona should be bisected by the line of junction of the bi-quartz polariscope, and the colours upon the corona should be carefully noted, not only near the line of junction, but also round the whole circumference of the dark moon. Any sudden transition from one colour to another should be especially recorded. Should any ray, or rift, or sector of colour with sharp edges be observed, it would be well to place the line of junction across such sector or rift, and note the colours upon its edges; the telescope carrying with it the line of junction might then be slowly withdrawn along the sector or rift from the limb of the moon outwards until all indications of the rift or its edges are lost-the observer, of course, noting the plane of polarisation within the rift, and whether it differs from that of the air polarisation in the neighbourhood of the sun.

A. C. RANYARD

\section{NOTES ON ECLIPSE PHOTOGRAPHY}

FCLIPSES of the sun occurred in I860, 1868 , and 1869 when photography was employed chiefly to obtain evidence as to the nature of the red prominences, and in all cases a telescope of some kind was used, the image being taken at the principal focus.

It is, however, preferable that instead of a telescope an ordinary photographic lens of long focus be employed. Such a lens may be a portrait combination, or single or compound lenses, adapted for landicape or copying work ; the conditions are that the image shall be as large as possible, and the lens quick-acting. These requirements were found to be combined in the lens I used at Syracuse, and which was made by Mr. Dallmeyer, and lent to me for the purpose of the expedition. The lens is $4 \mathrm{in.}$ in aperture, and has a focal length of $30 \mathrm{in}$, the image of the sun or moon being three-tenths of an inch in diameter. It is scarcely to be expected that there will be many lenses of this exceptional class available in India; but no doubt, there are many good landscape lenses of long focus which may be used, and if the images they give are not so large as those taken by the 4-inch "rapid rectilinear," the pictures obtained may have scientific value, although small. It is an interesting fact that at Oran Dr. Huggins had arranged with a lncal photographer to attempt soine pictures with a small lens, giving an image of about $\frac{z}{6}$ th of an inch in diameter.

In all cases it is strongly to be recommended that the best instrumen's be used. Instead of Dallmeyer's 4 inch

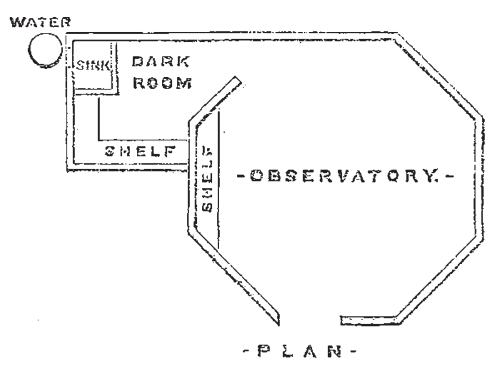

lens, it is suggested that lenses of the "rapid rectilinear" make, of still larger aperture, be used, as the focal length will be increased, and consequently a larger picture will be obtained, allowance, of course, being made for the increased exposure required, if the focal length of the lens has been made greater in proportion to the aperture.

It will be convenient to assume in what I have now to say that a lens of at least four inches aperture and thirty inches focal length will in all cases be used, and that it it will be corrected for the chemical rays.

Now an instrument of this kind, if used to photograph the sun's corona, will be useless if not mounted so as to follow the sun's apparent motion. The camera must, therefore, be mounted on a stand having clockwork motion. The stand of an equatorial telescope is what is required. The telescope may be removed, and the camera fixed in its Place-this for convenience only-or the camera may be fixed on the top of the telescope. It will, however, be better to remove the telescope.

In the observatory and dark room as used at Syracuse, the framework was of wood, as slight as possible consistent with stability, and was covered entirely with waterproof cloth, the dark room being lined with yellow calico, in some parts double. The floor was also covered with the waterproof cloth to keep down the dust. Instead of the cloth for the sides and the roof I should prefer very thin boards, and the roof only need be made watertight, the edges of the wood being made, if necessary, to overlap. If wood be used, one thickness of yellow calico will be sufficient. The 
cloth, if used alone for the sides and roof, is objectionable, owing to the possibility of wind tearing it away from the nails.

The importance of each photographic party being provided with a tent of the kind named cannot be too strongly irged. Residents in India will of course have no difficulty, but observers from England should prepare a tent at the nearest town to the place of observation, or, better still, take one with them. To unpack and erect our observatory and dark room required about a day, and to dismantle and repack it about three hours. To adjust and arrange the instruments will require about another day, and about two hours for the dismantling and packing. Much of our success at Syracuse depended on our being provided as described. The entire cost of the building, including waterproof cloth, yellow calico, and the fittings of the dark room was less than ten pounds. In the erection of a temporary construction of this kind, the shelter of a wall or building should be sought.

As these hints are for the practised photographer, and not for the tyro in the art, very little need be said about the process to be used. No dry process with which I am acquainted is adapted for the purpose. It may be suggested that the old positive process on glass would give good results, and I see no objection to using the negative process as well. Supposing six plates to be used, three of them could be developed as positives, and three as negatives, the exposinres being timed to suit either. The negatives taken at Syracuse were not strengthened or intensified, and although thes were developed as negatives they are almost as valuable as positives, as the detail is of so delicate a kind that very little of the outer corona can be seen when viewed by transmitted light. As positives, and viewed by refiected light, this detail is seen very perfectly. There is, however, detail of another kind in these negatives which can only be seen by transmitted light. The advaniage of the positive process is that the picture is chicfly on the surface, but at those parts where the light has been most active, the detail would probably be visible when viewed as negatives by transmitted light.

The size of the camera will be determined by the dimensions of the plates to be used. Plates 5 by $4 \frac{1}{2}$ inches will be quite large enough, and the camera will require to be slightly larger. The number of dark slides necessary will depend on the number of exposures to be made, and this again will be determined by the duration of the totality. In India, where the totality will be rather over two minutes, ir will perhaps be better not to attempt more than six exposures, therefore six frames will be needed. In Australia at least twelve plates could be exposed, the totality lasting over four minutes. The single frames used at Syracuse were found to be so handy and convenient to use that I am undecided in my opinion as to whether any advantage would be gained by using double or sliding frames. This is a matter which must be left to the choice of the operator. The frames may be made in the ordinary way, but the corners of the carrier or frame itself should be fitted with silver wire or glass for the plate to res $\downarrow$ upon; and as an extra precaution against defects likely to arise through some of the plates remaining in the frames half an hour, each corner may rest on blotting paper. In fixing on six as the number of plates to be used, I am assuming that they will all have to be prepared so as to be ready at the moment of totality; and I see no advantage to be gained by keeping an assistant in the dark room during that time; at most he could only prepare one plate, and I consider it preferable that every plate should be ready for immediate use. The preparation of these plates will require twelve minutes at least, and it is at this point and after the exposures are made that extra assistance would be valuable.

It was found at Syracuse that four baths of glass for the silver solution were sufficient; they were covered with brown paper to protect the plates from light. The dippers nay be of glass, or varnished wood, and it is better to be provided with both, in case of accident. The glass should be the best patent plate, selected, carefully polished, each one being marked with a cross in one corner, and stored in plate-boxes with the marks all in one position; and in all the subsequent operations this mark should be to the left hand-the reason for this will be seen presently.

The image obtained with a camera as described is small, and $i t$ is therefore undesirable that any part of it should be disfigured by position wires. The necessity for using wires may be overcome in a very simple manner. Let the ground glass focussing screen (which should be of the finest possible kind, patent plate glass before it receives its final polish) have pencil lines crossed diagonally, and a single ine horizontally across the centre of the plate. When the instrument is adjusted and stationary the image of the sun should travel parallel with this line. A plate should then be prepared, and a very small diaphragm being used in the lens, the instrument should then be moved quickly, so that the image of the sun leaves a trace which will appear after development. This will give the north poirt of the sun at the time of the eclipse, and serve as a key plate for all the pictures taken. The object of marking the corners of the plates will now be seen, and every plate used must be so held that in every operation the marked corner is touched by the forefinger or thumb of the left hand ; then there will be no doubt about the orientation of all the pictures.

Up to this point two operators will be suffecient, one to attend to the arrangement of the instruments, and who ought to have some astronomical knowledge, so as to be able to adjust the equatorial stand, and the other for strictly photographic work. Help will of course be required in the erection of the observatory and dark room. At the time of the eclipse two other assistants will be required, one to count seconds from the clock or chro. nometer, and the other to hand the plate frames to the assistant at the camera. If a clock beating seconds or half seconds were used, the assistant at the camera could do the counting, but volunteers will readily be found.

The plan adopted at Syracuse could not I think have been improved. Mr. Fryer was at the instrument making the exposures, while I was at the other end of the camera changing the frames. At the word "ready" Mr. Fryer took off the cap and counted the prescribed number of seconds. At his signal "done" the plate was changed, and so on through all the exposures. Captain Speight handed to me the frames and took them from me after exposure, thus saving twenty-five seconds of the time. Sapper Gardiner counted seconds aloud. At the signal of totality given by Mr. Fryer the counting commenced. At the third second the first exposure was made, the three seconds being allowed to make sure of absolute totality. A table of the times for the exposure of each plate had been prepared by Mr. Fryer beforehand, and this was kept in view so as to avoid the possibility of mistake. The times were arranged in the following order:-3, $8,30,15,8$ (the 6 th plate was exposed in the telescope camera, with thiree or four seconds to spare at the end). In India there will be time for the 6th plate to be exposed in the camera. On the day before and on the morning of the eclipse all the operators should be in their places to practise their different parts, as it will require the greatest possible care to avoid mistakes. Everything must be done deliberateíy and without the slightest hurry.

Previously to the last eclipse it had been supposed that the light of the Corona possessed very little actinism, and I had been strongly advised to give a full exposure. As, however, there was some doubt on the subject, it was determined to vary the exposures as stated; and unless the light of the Corona is not the same in all eclipses, I see no reason for suggesting any alteration in the time for exposing the plates to obtain different results, supposing the same kind of lens to be used. Allowance must 
of course be made for the altitude of the sun and the state of the weather at the various stations.

The dark frames were numbered from I to 6 , and the plates were exposed in the order in which they had been prepared, and the development proceeded in the same order.

Much of the delicate detail of the negatives is likely to be lost by vamishing. It is therefore preferable to cover them with glass, carefully binding the edges to exclude the air ; the glass cover should not touch the film. Instead of using an ordinary plate-box for the negatives, I prefer that each plate should have a slight frame similar to an ordinary "carrier," and these frames are then placed flat on a box prepared for them.

In counting seconds it is preferable that the assistant should count consecutively throughout the totality. Supposing the eclipse to last I 30 seconds, by counting from $I$ to 30 the operators know exactly the point arrived at after each exposure; and this is most important towards the end, as the last plate might be spoiled by the least mistake in this respect.

Artificial light of some kind will probably be required during the totality-certainly in the dark-room. We used the ordinary railway reading lamps. Boxes open on one side were provided, and in them the lamps were fixed. These boxes effectually protected the lights-without them the candles would have been exinguished by the wind.

It is better to assume that nothing will be found at the phice of observation but water, but as in India there may be some diffeulty in obtaining that necessary article sufficieritly pure for photographic purposes, it will be better to provide a small stivi, which will cost about $5^{\text {s. }}$ At Syracuse we used rain-water, which was sufficiently pure fer the purpose.

Those accustomed to photographic work in India will be aware of the necessary precautions to be observed to prevent the plates drying. At Syracuse we kept our observatory and dark-room well sprinkled with water and the glass plates, when they were in the dark frames, were covered on the backs with wet blatting-paper.

Much disappointment will be avotded if proper care be saken in packing the apparatus: All bottles and other glass articles should be placed in separate divisions and packed with cotton wool or paper cuttings. Packing-cases should be made very strong and bound with irion plates. By atterition to these matters the whole of the apparatus and chemicals were found on being unpacked at Syracuse to be altogether uninjured-the packing cases bear testimony to the rough usage they have undergone.

A. BROTHERS:

\section{CLIFION COLLEGE SCHOOL OF NATURAL SCIENCE}

TE have long insisted in NATURE on the extreme importance of science teaching in the higher grade schools in this country, and we are glad to find that at length its importance has begun to be recognised by the head masters themselves; so that, on the whole, the progress now being made in this direction is such that we may confidently expect that at novery distant future science may confidentil be provided for in all our superior schools. Foremost, if not positively the first among the schools in which the sciences are thus taught stands Clifton College, whaer the able direction of the Rev. J. Percival, in which scientific study is introduced to the utmost, and keenly purstied by the boys, with the encouragement of all their masters, the latter a most important consideration, and which, we are sorry to say, we cannot assert in reference to other schools of equal pretensions. There are several points of interest about the method of teaching at Clifton, and we are glad to have the opportunity of laying before our readers a sketch of the way in which the work there is carried on, together with a sketch of the museum, which, may well become the model of all school museums. Science is much indebted to Mr. Percival for the magnificent example he has set in science education.

Natural Science at this College is not a voluntary serbjeck, but forms a regular part of ordinary school work. The boys in the two highest classes on the classical side are allowed to choose between Science and German: throughout the rest of the school some branch of science is compulsory. In the Junior School Botany is taught, in the Upper School Chemistry and Physics. The boys on the classical side receive one lecture, those on the modern side two lectures a week on each of these latter subjects. The lectures are illustrated by experiments, accurate notes are exacted from the boys, and examinations are held: every fortnight or three weeks.

The accompanying is one of these fortnightly papers :MAGNETISM

I. Soft iron can never be permanently magretised, yet a piece of soft iron in contact with a magnet hecomes a magnet. Why?

2. What do you understand by coercive force, and magnetic satzeration?

3. How is magnetism infuenced by heat?

4. Mention the substances which are attracted by a magnet in addition to iron.

5. State one or more of the methots by which steel bars may be magnetised.

6. What is the dectination or variation of the magnetic needle and the present extent of it?

\section{CHEMISTRY}

a. For First and Second Sets; Modern Side only.

I. Mention the oxygen compounds of phosphorus, and the actions of water wpon them.

2. Give an account of arsenicum and its chief characteristics.

3. What are the constituents and characteristics of arseniuretted hydrogen?

4. What is "white arsenic," and how may it be prepared?

5. Vou are given a liquid suspected to contain arsenic; by what means would you examine it?

b. For all other Forms.

r. Ammonia gas, and hydrochloric acid gas, are brottght into. contact : what is the resulting compound, and to what may it be compared?

2. What is anmonitm? Describe the formation and appearance of ammonium amalgam.

3. What do you know of chloride of nitrogen?

4. What is nitric acid, and by what means may it be procured?

5. State the action of nitric acid upon metals, - copper, tin, antimony, -and the general tendency of the acid.

\section{BOTANY}

Third A. and B. onIy. (To be written on separate paper only)

I. Describe the following forms of roots:-tap, napiform, patemorse, tubercular.

2. How are firids absorbed by the roots?

3. Show clearly the true nature of the various forms of the bulb.

4. What is a "rhizome" (or root-stock)? Compare it with a "corm."

5. Give an account of the structure of the stem in a common potato.

6. Why is it that plants and animals have a mutual dependence on each other for their life?

Special classes are formed for those who wish to go deeper into these subjects, or to take up others. Thus, there are special classes studying Chemistry, Physics, Zoology, Physiology, Botany, Physical Geography, and Civil Engineering.

Facilities are also afforded for learning science practically. In the Chemical Laboratory about twenty boys study analysis. A Physical Laboratory has been built and will be opened next September. It will accommodate about twenty pupils, and its arrangements will be based 